Viso - Cadernos de estética aplicada Revista eletrônica de estética

ISSN 1981-4062

$N^{\circ} 2$, mai-ago/2007

http://www.revistaviso.com.br/

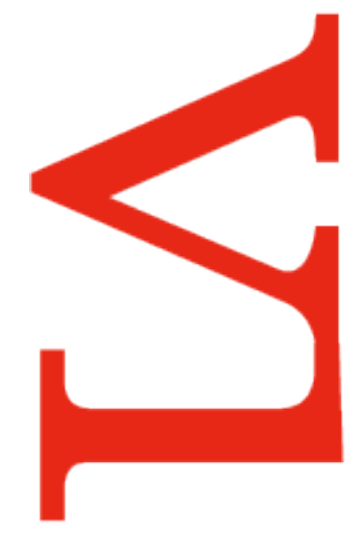

$\sim$

\title{
Sobre o tapete da verdade: Benjamin e Hölderlin \\ Claudia Castro
}




\section{RESUMO}

Sobre o tapete da verdade: Benjamin e Hölderlin

Este artigo apresenta a leitura que Walter Benjamin faz da poesia hölderliniana no ensaio Dois poemas de Friedrich Hölderlin (1914/1915). Destacando a relevância desta lírica na formação do pensamento benjaminiano, o trabalho procura esclarecer o papel da crítica literária na construção de um conceito superior de experiência, objetivo primeiro do filósofo.

Palavras-chave: Benjamin - Hölderlin - poesia - crítica - experiência

\section{ABSTRACT}

About the carpet of truth: Benjamin and Hölderlin

This article presents Walter Benjamin's interpretation of Hölderlin's poetry in the essay Two poems of Friedrich Hölderlin (1914/1915). Underlining the relevance of this lyric in the shaping of Benjamin's thought, the work searches to elucidate the literary criticism's role on the construction of an elevated concept of experience, the philosopher's major aim.

Keywords: Benjamin - Hölderlin - poetry - criticism - experience 
CASTRO, C. "Sobre o tapete da verdade: Benjamin e Hölderlin". In: Viso: Cadernos de estética aplicada, v. I, n. 2 (mai-ago/2007), pp. 47-57.

DOI: $10.22409 / 1981-4062 / v 2 i / 40$

Aprovado: 25.07.2007. Publicado: 12.08.2007.

(C) 2007 Claudia Castro. Esse documento é distribuído nos termos da licença Creative Commons Atribuição-NãoComercial 4.0 Internacional (CC-BY-NC), que permite, exceto para fins comerciais, copiar e redistribuir o material em qualquer formato ou meio, bem como remixá-lo, transformá-lo ou criar a partir dele, desde que seja dado o devido crédito e indicada a licença sob a qual ele foi originalmente publicado.

Licença: http://creativecommons.org/licenses/by-nc/4.0/deed.pt BR

Accepted: 25.07.2007. Published: 12.08.2007.

(C) 2007 Claudia Castro. This document is distributed under the terms of a Creative Commons Attribution-NonCommercial 4.0 International license (CC-BY-NC) which allows, except for commercial purposes, to copy and redistribute the material in any medium or format and to remix, transform, and build upon the material, provided the original work is properly cited and states its license.

License: http://creativecommons.org/licenses/by-nc/4.0/ 
Acaso não conheces numerosos vivos? Sobre o verdadeiro não desliza teu pé como sobre um tapete? Vá, meu Gênio, avance Nu na vida e não tenhas medo!

Seja oportuno tudo o que te suceda! Com a alegria conciliado! Que poderia ofender-te coração? Que impede que sigas teu caminho?

Hölderlin

Em Walter Benjamin o pensamento radical irrompe da mais profunda imersão na tradição. Ele não é nunca uma criação que surge do nada, mas o efeito de uma tradução, de uma leitura que opera deslocamentos, transposições e rupturas. Assim se explica o íntimo parentesco que une a filosofia benjaminiana e a lírica hölderliniana: a poesia é irmã da filosofia na medida em que consiste numa "configuração" cujo "teor de verdade" constitui o "problema supremo" desta filosofia. Consagrado precisamente à interpretação da poesia hölderliniana, o primeiro grande trabalho de Benjamin, o ensaio intitulado Dois poemas de Friedrich Hölderlin, é onde o filósofo nos apresenta seu novo método do comentário estético - a leitura imanente das obras -, que lhe permitirá o alargamento do conceito de experiência filosófica, objetivo primeiro por ele pretendido.

Ao fazer de sua obra a construção de uma filosofia da experiência que ultrapassa os limites impostos por Kant - aqueles da experiência subjetiva sensível espaço-temporal -, que seja capaz de incluir a dimensão da religião e da história, a experiência considerada em sua estrutura total como "experiência temporal", Benjamin se encontra com Hölderlin, cuja formação filosófica, semelhante à sua, emerge de uma extensa leitura de Kant e também exige ultrapassar a crítica kantiana, radicalizando-a.

Em seu texto de 1918, Sobre o programa de uma filosofia futura, Benjamin afirma que Kant, prisioneiro da estreita vision $d u$ monde iluminista desprovida de "potências espirituais" capazes de oferecer conteúdo a uma experiência mais plena, teria negligenciado a articulação necessária entre o conhecimento e a linguagem. Esfera de total neutralidade em relação aos termos de sujeito e objeto, para Benjamin a linguagem constitui o lugar lógico da verdadeira metafísica, a morada da verdade filosófica: uma "pura linguagem" [reine Sprache], sem sujeito e desprovida de qualquer significação que Ihe seja exterior. Esta é também a linguagem buscada por Hölderlin. De acordo com Rainer Nagële, Hölderlin sustentou mais do que qualquer outro poeta moderno o ideal de uma língua pura para a poética, num tempo em que o ideal estético oposto, aquele da expressão pessoal, iniciava seu domínio. Como canto sublime e puro, sua poesia, longe de ser expressão da interioridade, da vivência da consciência, exige o descentramento do sujeito, o mergulho do poeta em seu objeto como em um abismo. Um ideal que diz respeito à esfera intersubjetiva onde o Deus emerge. 
Escrito entre 1914 e 1915, o estudo de Benjamin sobre Hölderlin foi concebido nos meses que se seguiram à morte de seu maior amigo nesta época, o poeta Fritz Heinle, com quem partilhava uma "pura comunidade espiritual". Em 8 de agosto de 1914, levado pelo desespero da guerra que acabara de irromper, Heile se suicida junto com a noiva Rika Seligson. Segundo o biógrafo Bern Witte, "para Benjamin, esta morte se tornou uma forma da experiência original". ${ }^{1}$ A sobrevivência à morte de Heinle tomou em sua existência uma significação crucial: ao sobreviver à morte do poeta, ele dá testemunho de sua produtividade, de sua destruição e da realização de seu sentido na morte. Heinle representava para Benjamin o "ser produtivo", o poeta; para si, ele reservara o papel de homem de letras cuja tarefa era "decifrar o espiritual em todas as manifestações da vida". ${ }^{2}$ Se ao longo de toda a vida a lembrança do amigo the surge envolta "de uma espécie de mistério sagrado", é porque sua morte the proporcionou o vislumbre de que "a pureza do espírito deve ser buscada não na vida, mas na linguagem poeticamente formada". ${ }^{3}$ Uma pureza espiritual que só se torna eficaz e visível com a linguagem da sobriedade que caracteriza a prosa crítica: tal é o papel infinitamente poderoso e a tarefa salvadora do criticismo nesta filosofia.

Aos olhos de Benjamin, a figura de Heinle se confunde com a de Hölderlin em seus últimos anos, e compõe a "nova imagem ideal da existência humana". ${ }^{4}$ Dedicado a Heinle, o ensaio sobre Hölderlin eleva o poeta ao posto de salvador do mundo. Ele é o "princípio formal" que funda a "unidade" capaz de sustentar um mundo em desagregação. No entanto, isso só é possível para aquele que se abandona ao perigo, que, em sua morte, estende o perigo às dimensões do próprio mundo, e, ao mesmo tempo, o vence. Porque o perigo não ameaça somente o corajoso, mas o mundo mesmo: é a violência mítica que devasta a história e crava a morte no seio da vida. Compreendida em sua mais profunda significação, a coragem do poeta, que o investe do sentido e do destino da cultura, é a coragem de morrer, de lançar-se no abismo. Ao entregar-se à morte, dissolvendo-se, ele anula sua ameaça e ao mesmo tempo confere ao mundo a mais pura expressão. Nesta interpretação da literatura, o destino do poeta é trágico. Ele deve desaparecer necessariamente para cumprir a tarefa que lhe é própria, a construção de uma "estrutura inteligível do mundo". ${ }^{5} \mathrm{Em}$ seu estudo da lírica hölderliniana, Benjamin faz da morte o princípio que confere à imagem do poeta um contorno definitivo, ao seu texto um sentido, e à sua obra esplendor e verdade. Eis o arquétipo de toda poesia que dominará sua teoria da lírica sob o nome de "sobriedade". Benjamin escreve:

No sentido desta concentração, as coisas aspiram à existência enquanto pura idéia e determinam o destino do poeta no puro mundo das formas. A plástica da forma se revela como sendo o espiritual. ${ }^{\circ}$

A teoria da lírica benjaminiana se constrói em torno do conceito interpretativo central de poetizado [das Gedichtete]. Distanciando-se tanto da filologia quando da biografia que caracterizavam a estética literária que the é contemporânea, o método crítico benjaminiano é filosófico: trata-se de operar uma leitura imanente ao poema, despojada 
de qualquer critério heterônomo, para encontrar sua "forma interna", aquilo que Goethe chamava de "teor" [Gehalt]. Este é o poetizado, definido por Benjamin como "a unidade sintética de duas ordens, aquela do espírito e aquela da intuição sensível". ${ }^{7}$ Ele constitui também a "tarefa do poeta", cuja grandeza e seriedade deve preceder e determinar todo juízo sobre um poema. No entanto, Benjamin esclarece, não cabe ao crítico julgar a maneira como o poeta desempenha essa tarefa. É do poema, da própria obra, que se infere essa tarefa: "ela deve ser compreendida como o pressuposto da poesia, como a estrutura espiritual-intuitiva [geistig-anschauliche Struktur] do mundo do qual o poeta é testemunha". ${ }^{8}$ Ao mesmo tempo imanente e externo ao poema, o poetizado, formado tanto pelo poema quanto pela vida, dá forma a ambos. Se ele é, a uma vez, o produto e pressuposto da poesia, é também o objeto último e o resultado da crítica.

O poetizado possui uma temporalidade paradoxal: é logicamente anterior e cronologicamente posterior aos poemas singulares. Se ele preexiste como pressuposto da poesia, enquanto estrutura do mundo, só pode ser pensado pela crítica uma vez que os poemas tenham sido escritos. Conforme a relação dialética entre as obras de arte e o conceito benjaminiano de origem [Ursprung], que caracteriza a emergência da idéia, as obras singulares configuram uma resposta, um conteúdo histórico que desde a origem aspira à ideação filosófica, mas essa ideação só pode interrogar um conteúdo que encontra a sua resposta concreta nessas obras. Incompatível com qualquer aspiração nostálgica de retorno a um fundamento primeiro, de regressão a um ser original, a origem, em Benjamin, diz respeito ao surgimento do novo, um "teor de verdade" que é, essencialmente, resultado. O poetizado que cabe à crítica detectar nas obras é a idéia. Ela não é abstrata, não é da ordem de um indizível não enunciado na poesia que caberia ao crítico representar de forma discursiva. O poetizado, enquanto idéia, estrutura inteligível do mundo, é algo de lingüístico: a experiência silenciosa do sentido, que jaz incrustrada na materialidade das obras, deve ser ressuscitada pela crítica, cuja tarefa é expô-la novamente.

Nesta filosofia, os produtos do poema e da crítica fundem-se um no outro, e a diferença tênue que separa o texto literário do texto filosófico tende à identidade. Porém, se tal identidade é proclamada antes de ser produzida, com a paciência minuciosa, a tenacidade e a intensidade da leitura, ela se dissolve. Porque a força da ressonância mora na diferença entre os textos, onde uma nova linguagem vem à luz em sua mútua reflexão. Crítica e poesia se interpenetram ao aproximarem-se daquela língua da qual toda expressão dá testemunho sem se confundir com ela: a pura língua do poetizado, onde tanto a poesia quanto a crítica escapam da expressão subjetiva e "o significado salta de abismo em abismo até quase perder-se nas insondáveis profundezas da linguagem". ${ }^{9}$

A poesia é tradução do mundo. Seu núcleo, o poetizado, é uma estrutura espiritualintuitiva do mundo, uma linguagem. Ele não representa a visão de mundo do autor. Ao contrário, constitui o rastro de seu dilaceramento e de seu pedido de redenção. Há uma 
exigência objetiva inerente ao poetizado. Pois a questão que orienta esta estética da arte poética é a definição de um critério objetivo de análise imanente das obras. Enfrentando a dificuldade da discussão estética pós-kantiana, Benjamin quer estabelecer as bases sobre as quais um juízo estético pode ser fundado, definindo um "modo de necessidade" inerente às obras, que não se confunda com a exigência de uma verdade meramente teórica. Ao contrário de Kant, para Benjamin o juízo estético pode ser justificado. Mas a "verdade" das obras que justifica a presença das mesmas é estritamente estética. Jamais poderia ser formulada em termos meramente teóricos, independentes das obras, como propôs o Idealismo. O criticismo benjaminiano arranca a arte do arbítrio da expressão subjetiva e nela descobre uma lei rigorosa: trata-se de conferir a uma estética, centrada não sobre o conceito de gosto mas sobre aquele de obra, uma fundamentação transcendental de tipo kantiano. Assim se compreende a bela fórmula de Novalis citada por Benjamin: "toda obra de arte possui em si um ideal a priori, uma necessidade de existir". Como ideal do poema, o poetizado é sua verdade enfática. Reconstruí-lo é a tarefa da crítica. Para tal, ela deve "fazer abstração de certas determinações, para colocar à luz a relação interna, a unidade funcional dos outros elementos". ${ }^{10}$ Porque a esfera particular de cada poema que se isola é o que nele toma forma objetiva :

Nela se revelará o domínio característico que contém a verdade da poesia. Esta "verdade", que justamente os artistas mais sérios atribuem com tanta insistência às suas criações, nós a entenderemos como a objetividade [Gegenständlichkeit] de seu ato criador, como a realização acabada da tarefa artística específica de cada obra. ${ }^{11}$

No pensamento benjaminiano, esta é a forma mais autêntica de verdade que nos é dada. Expressão do mundo, a obra poética confere a uma configuração da vida uma coerência que possui a necessidade de uma lei natural. Na esteira dos românticos alemães, Benjamin utiliza o termo "mito" como equivalente ao poetizado, o conteúdo filosoficamente decifrável do poema. Para que haja obra, o poeta deve elaborar sua própria coerência poética, construir de seu próprio "mito": a estilização, no poetizado, da vida verdadeira, exemplar, segundo as condições históricas que Ihe são dadas. Uma coerência, um sentido, a coesão do mundo que se constrói na própria forma. Aqui jaz a razão da diferença que, na leitura de Benjamin, afasta os dois poemas de Hölderlin em questão - "Coragem de poeta" [Dichtermut] e "Timidez" [Blödigkeit] -, muito próximos por sua temática e separados pela pequena distância de apenas um ano, marcado todavia pelos acontecimentos decisivos que precederam a longa loucura do poeta.

Na primeira versão, "Coragem de poeta", esta coerência - que podemos chamar também de "íntima coesão" [innerster Zusammenhang] do mundo poético - não está plenamente realizada. Benjamin aí identifica uma coerência emprestada, que permanece no nível do conteúdo, claramente referido à mitologia grega: a primeira versão é mitológica. Já em Timidez, a última versão, Hölderlin elabora seu próprio mito, sua própria coerência poética, e o poetizado, na íntima ligação entre forma e conteúdo, se apresenta em toda a sua "unidade". 
Ao fim de seu estudo, após uma análise preciosa dos dois poemas, Benjamin constata que no poema do último período hölderliniano "a fronteira do poetizado com relação à vida foi avançada o mais longe, onde a energia da forma interna se revela tão mais potente que a vida significada é mais fluída e informe". ${ }^{12}$ É aí que se torna visível a "unidade do poetizado" na inseparabilidade entre a forma e o conteúdo. Se os dois poemas se relacionam no poetizado, que permite a comparação, tal deve ser buscado em uma certa "atitude face ao mundo" 13 , a coragem diante da morte. Enquanto na primeira versão a coragem é ainda concebida como "caráter individual", homem e mundo se colocam frente à frente e não compartilham um "mundo concreto", em "Timidez", "à medida que ela é mais profundamente compreendida, devém menos um caráter individual que uma relação do homem ao mundo e do mundo ao homem". ${ }^{14} \mathrm{Em}$ "Coragem de poeta", Hölderlin já tentava descobrir uma "profunda relação com a morte", mas esta se mostrava apenas indiretamente. A vida ainda era vista como uma condição prévia para a morte, a forma surgia da natureza e o perigo da morte era vencido pela beleza. Mas a "dualidade do homem e da morte só pode [...] repousar sobre um sentimento pouco rigoroso da vida". ${ }^{15}$ Do momento em que o poetizado passa a traduzir uma mais profunda ligação, a coragem, enquanto "princípio espiritual", dá forma à vida. A coragem que é, em Benjamin, o "entregar-se ao perigo que ameaça o mundo"16, "o sentimento da vida próprio àquele que se lança ao perigo, que morrendo, estende portanto o perigo ao próprio mundo e, ao mesmo tempo, o supera". ${ }^{17} \mathrm{Na}$ morte do corajoso, o perigo que atingia o mundo não o ameaça mais. Toda beleza de "Timidez" decorre daí. O perigo está agora inteiramente dominado pelo "princípio espiritual" onde o poeta-herói e o mundo são um só: a coragem. Benjamin a descreve como:

[...] a mais íntima identidade entre o poeta e o mundo, da onde decorrem aqui todas as identidades entre o sensível e o espiritual. Tal é o fundamento onde sempre de novo a forma separada se abole na ordem espaço-temporal, onde ela é suprimida como informe, omniforme, processo e existência, plástica temporal e acontecer espacial. ${ }^{18}$

A experiência lírica aqui é aquela que transforma a dualidade entre o poeta e a morte na construção da unidade de um "mundo poético morto", "saturado de perigos". Esse pensamento absolutamente histórico e temporal transforma a atitude propriamente poética em timidez, que poderíamos nomear também de humildade. Lançado no centro da vida histórica, ao poeta resta apenas uma "existência imóvel": a "plena passividade que é a essência mesma do corajoso". Princípio da forma, da limitação, o poeta produz a cesura imperiosa, a separação que o afasta de todas as formas da representação, garantindo-lhe a unidade do mundo. Para a compreensão do sentido mais profundo da lírica hölderliniana mais tardia, Benjamin lança mão de uma categoria da linguagem e da arte cuja importância foi o próprio Hölderlin quem talvez tenha melhor avaliado: a cesura [Casür]. Em suas Observações sobre o Édipo, a propósito do transporte trágico, o poetapensador a definiu com precisão:

O transporte trágico é, propriamente, vazio e o mais desprendido. Por isso, na consecução rítmica das representações em que se apresenta o transporte, faz-se necessário aquilo que, na dimensão silábica, se costuma chamar de cesura, a palavra 
pura, a interrupção anti-rítmica a fim de se encontrar a alternância capaz de arrancar as representações numa tal culminância que o que aparece não é mais a alternância das representações e sim a própria representação. ${ }^{19}$

Enquanto palavra pura, sopro que corta o verso, a cesura evoca um instante de suspensão, sobrevôo, que impõe uma ruptura nas formas tradicionais da representação - seja no sentido habitual da linguagem, na linearidade monótona do tempo da história, ou na pretensão de totalidade harmoniosa das obras de arte. A cesura, como Benjamin indicou em seu ensaio incomparável sobre as Afinidades eletivas de Goethe, nos leva ao sem-expressão [das Ausdrucks-lose], ao silêncio sublime onde habita a verdade da linguagem e da arte. Ela evoca a mudez de uma experiência intensiva do tempo, paralisada, onde a chance do novo pode se dar. A "santa sobriedade" que, como já se notou, exprime a tendência que rege as obras tardias de Hölderlin, aponta, ultrapassando a "aparência de reconciliação" na beleza, para esta verdade sublime: o "princípio oriental, místico", capaz de garantir a coesão intensa do mundo. Na palavras de Schiller, "o verdadeiro segredo do mestre artista consiste em destruir a matéria pela forma". Benjamin acredita que a linguagem poética está embebida da mesma verdade buscada pela filosofia, porque a ambição do poeta é filosófica. Assim, a tarefa diretriz da crítica estética é repetir a ruptura, operar uma vez mais a cesura, num gesto violento de "mortificação das obras" que as transforma em ruína, e, nesta destruição, permite a salvação de seu sentido no presente.

A unidade sintética entre o sensível e o espiritual, o "teor" que Benjamin descobre na lírica tardia de Hölderlin, faz do próprio exercício da crítica a construção de sua filosofia de uma "experiência superior". A interpretação da poesia hölderliniana se apresenta como um aspecto da expansão da noção de experiência filosófica e não apenas a sua aplicação. Desta forma, o estudo de Benjamin sobre Hölderlin inaugura uma nova relação entre filosofia e literatura, onde tanto uma quanto a outra são transformadas, garantindo à poesia sua dignidade filosófica. Na experiência poética de Hölderlin, relançada sobre ele por Benjamin, o pensamento benjaminiano encontra o alimento para a elaboração de uma nova concepção de verdade, radicalmente histórica e teológica, marcada pelo tempo, pela morte e pelo desejo de salvação. Uma verdade que se mostra na linguagem, "o tapete do verdadeiro". Tal é a pura língua, língua-cristal, muda, inexpressiva e criativa que constitui o que querem dizer todas as línguas, e que pertence às formas mais elevadas de expressão lingüística.

Uma das preocupações centrais que orienta a obra de Benjamin é aquela de como pode o moderno ter uma tradição. Sua leitura de Hölderlin nos ensina que a tradição, na modernidade, só pode ser salva por um trabalho de interpretação que parte da ruptura. Enquanto união misteriosa do sensível e do espiritual, a tradição é uma construção que depende da humildade corajosa diante do tempo, da morte, e do silêncio coercitivo da linguagem. 


\section{BIBLIOGRAFIA COMPLEMENTAR}

BENJAMIN, W. “Über Sprache überhaupt und über die Sprache des Menschen”. In: Gesammelte Schriften. Frankfurt am Main: Suhrkamp, 1977. Traduções: Gandillac, Rochlitz e Rusch, "Sur le langage en general et sur le langage humain". In: CEuvres. Éditions Gallimard: Paris, 2000; Maria Luz Moita, Maria Amélia Cruz e Manuel Alberto, "Sobre a Linguagem em Geral e sobre a Linguagem Humana”. In: Sobre Arte, Técnica, Linguagem e Política. Lisboa: Relógio D’Água, 1992.

. "Uber das Programm der kommenden Philosophie". In: Gesammelte Schriften. Frankfurt am Main: Suhrkamp, 1977. Tradução francesa: Gandilac, Rochlitz e Rusch, "Sur le programme de la philosophie qui vient”. In: CEuvres. Éditions Gallimard: Paris, 2000.

"Goethes Wahlverwandtschaften". In: Gesammelte Schriften. Frankfurt am Main: Suhrkamp, 1977. Traduções: Gandillac, Rochlitz e Ruch, "Les Affinités electives de Goethe”. In: CEuvres. Éditions Gallimard: Paris, 2000; Graciela Calderón e Griselda Mársico, "Las afinidades electivas de Goethe". In: Dos ensayos sobre Goethe. Barcelona: Editorial Gedisa, 1996.

"Ursprung des deutschen Trauerspiel". In: Gesammelte Schriften. Frankfurt am Main: Suhrkamp, 1977. Tradução brasileira: Sergio Paulo Rouanet, Origem do drama barroco alemão. São Paulo: Brasiliense, 1984.

ESCOUBAS, E. "Hölderlin et Walter Benjamin: L'Abstraction lyrique". In: L'Herne, $\mathrm{n}^{\circ}$ 57. Paris: Éditions de L'Herne, 1989.

NÄGELE, R. "Benjamin's ground”. In: Benjamin's ground: new readings of Walter Benjamin. Detroit: Wayne State University Press, 1988.

\section{* Cláudia Maria de Castro é professora da PUC/RJ.}

${ }^{1}$ WITTE, B. Walter Benjamin. Une biografie. Paris: Les Éditions du Cerf, 1988, p. 36.

2 Ibidem, p. 35.

${ }^{3}$ Ibidem, p. 37.

${ }^{4}$ Ibidem.

${ }^{5}$ Ibidem.

6 BENJAMIN, W. "Zwei Gedichte von Friedrich Hölderlin". In: Gesammelte Schriften, v. II.1. Frankfurt am Main: Suhrkamp, 1977, p. 119. Tradução francesa: Maurice de Gandillac, Rainer Rochlitz e Pierre Rusch. "Deux poèmes de Friedrich Hölderlin”. In: CEuvres, v. I. Éditions Gallimard: Paris, 2000, p. 114.

${ }^{7}$ Ibidem, p. 106; tr. fr., p. 92.

${ }^{8}$ Ibidem, p. 105; tr. fr., p. 92.

${ }^{9}$ BENJAMIN, W. "Die Aufgabe des Übersetzers". In: Gesammelte Schriften, v. IV.1. . Op. cit., p. 21. Traduções: Gandillac, Rochlitz e Rusch, "La tâche du traducteur". In: CEuvres, v. I. Op. cit., p. 261; "A tarefa do tradutor". In: Cadernos do Mestrado/UERJ. Rio de Janeiro: UERJ, 1992, p. xxii. (modificada).

${ }^{10}$ BENJAMIN, W. "Zwei Gedichte von Friedrich Hölderlin”. Op. cit., p. 106; tr. fr., p. 93.

${ }^{11}$ Ibidem, p. 105; tr. fr., p. 92.

12 Ibidem, p, 122; tr. fr., p. 118.

${ }^{13}$ Ibidem, p. 123; tr. fr., p. 119. 


\author{
${ }^{14}$ Ibidem. \\ 15 Ibidem. \\ ${ }^{16}$ Ibidem, p. 123; tr. fr., p. 120. \\ ${ }^{17}$ Ibidem. \\ ${ }^{18}$ Ibidem, p. 124; tr. fr., p. 120.
}

${ }^{19}$ HÖLDERLIN, F. "Anmerkungen zum Ödipus". In: Sämtliche Werke, v. 10. München: Luchterhand, 2004, p. 155. Traduções: D. Naville e François Fédier, "Remarques sur \&Oelig;dipe”. In: CEuvres. Paris: Gallimard, 1967, p. 952; Márcia C. de Sá Cavalcante, "Observações sobre o Édipo". In: Reflexões: Friedrich Hölderlin. Rio de Janeiro: Relume-Dumará, 1994, p. 94. 